\title{
ASSESSMENT OF NATIVE ARBUSCULAR MYCORRHIZAL FUNGI ASSEMBLAGES UNDER DIFFERENT REGIMES OF CROP ROTATION
}

\author{
MAGURNO, F*. - SASVÁRI, Z. - POSTA, K. \\ Microbiology and Environmental Toxicology Group, Plant Protection Institute, \\ Szent István University \\ Pater K. street 1, 2100, Gödöllö, Hungary \\ (phone: +3628522 910; fax: +3628410 804) \\ *Corresponding author \\ e-mail:franco.magurno@gmail.com \\ (Received $18^{\text {th }}$ May 2015; accepted $26^{\text {th }}$ Sept 2015)
}

\begin{abstract}
Given the potential benefits of arbuscular mycorrhizal fungi (AMF) to agricultural productivity, the impact of agricultural practices on the AMF communities has been aim of an increasing number of studies. Using molecular markers on the large subunit rDNA, we investigated the influence of different long-term crop rotations on the structure and composition of the indigenous AMF community, at the experimental field in Martonvásár, Hungary. Only phylotypes belonging to the family Glomeraceae were detected. Comparing the root and soil AMF assemblages no significant correlations were found between the rotation systems and the composition of the communities. However the analysis of the diversity and the net relatedness index suggested an influence of the number and identity of the crops in rotation on the structure of the AMF communities.
\end{abstract}

Keywords: arbuscular mycorrhizal fungi; crop rotation; maize

\section{Introduction}

Arbuscular mycorrhizal fungi (AMF) are obligate root symbionts which form symbiotic relationships with the majority of land plants including the ten most important human food crops (FAO, 2012). Among outputs of AMF symbiosis are considered of great interest an improved uptake of nutrients from soil in exchange for plant-assimilated carbon (Smith and Read, 2008) as well as a partial protection against root pathogens and drought stress (Pozo and Azcón-Aguilar, 2007; Augé, 2001). Given the potential benefits to agricultural productivity (Lekberg and Koide, 2005) AMF have received increasing attention for their possible utilization in a more sustainable agriculture without negative impacts on valuable natural resources. In the last few decades a significant effort has been dedicated to develop suitable formulations for AM fungal propagules and appropriate means for their application to the field (Gianinazzi and Vosatka, 2004). However the production and application of AMF inoculum on a large-scale can be difficult both for the high costs of propagation techniques and for the unpredictable outcome of the establishment among the native AMF community (Berruti et al., 2014). As in alternative or in concurrence with AMF inoculation, the manipulation of indigenous AMF communities through management of agricultural practice and edaphic factors has been reckoned to lead to a profitable capitalization of AMF at the field scale (Verbruggen et al., 2013). Beside stochastic-neutral processes (Dumbrell et al., 2010; Lekberg et al., 2012) several studies have revealed how nichebased mechanisms could be involved in the structuring of AMF communities. Among the edaphic factors, changes in soil nutrient availability, mainly nitrogen $(\mathrm{N})$ and 
phosphate (P), soil pH and soil type (Balestrini et al., 2010; Oehl et al., 2010) were identified as major drivers of AMF community composition. Furthermore abundance and diversity of AMF have been found to be negatively associated with intensive agricultural practices such as tillage, high levels of mineral fertilization, herbicide application and frequent fallow periods with negative effects on fungal agroecosystem functions and services (Bardgett et al., 2005). Recently a new piece was added to the puzzle. Beside AMF diversity, the level of relatedness among AMF taxa co-occurring in the root has been shown to affect the outcome of the symbiosis (Roger et al., 2013). In the study, more phylogenetically related were the taxa, more high was the ability of symbionts to coexist consuming less resources in the competition and providing more benefits to the plant. Although the research was carried out using AMF isolates belonging to the same species, the level of relatedness among taxa offers a new perspective in the interpretation of the AMF community diversity.

Crop rotation is a widespread agronomic practice that exhibits general beneficial aspects associated with maintenance or improvement of soil fertility and decreased reliance on agricultural chemicals. Despite its importance, the effects of crop rotation on AMF communities are not widely investigated. Root colonization and spore abundance have been found to be affected by the presence of non-host crops in the rotation (Arihara and Karasawa, 2000). Monoculture was reported to host extremely low AMF diversity (Burrows and Pfleger, 2002; Oehl et al., 2003). Molecular studies regarding the diversity of AMF communities under different regimes of crop rotation are scarce and they have not yet given an unambiguous picture. In some cases the practice of crop rotation was shown to promote an increase of diversity in AMF communities (Hijri et al., 2006; Higo et al., 2013), while in others monocropping revealed an unexpected high level of AMF richness (Magurno et al., 2014a).

In the present work we propose to investigate root and soil AMF assemblages under different regimes of crop rotation, evaluating the differences in terms of diversity and relatedness of the taxa, and provide a more clear interpretation of the effect of crop rotation on the AMF community.

\section{Materials and methods}

\section{Study site and sampling}

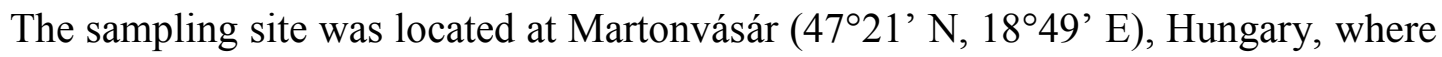
an experimental field was established in 1958 by the Agricultural Research Institute of the Hungarian Research Academy of Sciences.

The crop rotation experiment was a two-factorial split-plot with four replications. The main plots were the crop sequences and the subplots were the fertilizer treatments, in a randomized design (Berzsenyi et al., 2000). The main plots consisted of seven crop sequences: 1) maize monoculture; 2) wheat monoculture; 3) 3 years alfalfa -5 years maize; 4) 3 years alfalfa -5 years wheat; 5) 2 years wheat -2 years maize; 6) 3 years alfalfa -3 years maize -2 years wheat; 7) maize - spring barley - peas - wheat (Norfolk crop rotation). The main plots were split in five subplots $\left(7 \mathrm{~m} \times 7 \mathrm{~m}=49 \mathrm{~m}^{2}\right)$ representing the fertilization treatments as follow: a) control; b) manure + NPK $\left(60 \mathrm{t} \mathrm{ha}^{-}\right.$ 1 manure every 4 years); c) crop residue + NPK; d) NPK; e) NPK (calculated for $15 \mathrm{t}$ $\mathrm{ha}^{-1}$ maize yield and $10.5 \mathrm{tha}^{-1}$ wheat yield). 
Crops were harvested in the end of October, followed one month later, by a conventional tillage of $20 \mathrm{~cm}$ depth. Weeds and insects were controlled by pesticide treatments in all plots as described in detail by Magurno et al. (2014a).

Four cropping systems were chosen for sampling: maize monoculture (CR 1) as a control, alfalfa-maize (CR 3), wheat-maize (CR 5) and Norfolk type rotation (CR 7). Two subplots (two replications), at least $40 \mathrm{~m}$ distant, were sampled per each cropping system choosing only the subplots without fertilization (treatment a). Three plants were randomly collected from each subplot on June 2012, when maize was present in all the trials except in Norfolk type with wheat. Twenty-four plants with a soil core were collected (4 rotation systems $\times 2$ parcels $\times 3$ plants). The roots were stored in separate plastic bags in a cooler box $\left(\sim 4^{\circ} \mathrm{C}\right)$ and then at the temperature of $-20^{\circ} \mathrm{C}$ until processing. Chemical analysis of soil (Table 1) were performed separately on samples collected per each parcel by Soil and Plant Testing Laboratory of Faculty of Horticulture, Kecskemét College, accredited by the Hungarian Standard Institution (MSZ).

Table 1. The major physicochemical properties in the upper $20 \mathrm{~cm}$ soil layer of the experimental soils in different treatments

\begin{tabular}{|c|c|c|c|c|c|c|}
\hline Treatments & $\underset{(\%)}{\text { Humus }}$ & $\underset{(\mathbf{K C l})}{\mathbf{p H}}$ & $\begin{array}{c}\mathrm{CaCO}_{3} \\
(\%)\end{array}$ & $\begin{array}{c}\mathrm{P}_{2} \mathrm{O}_{5} \\
\left(\mathrm{mg} \mathrm{kg}^{-1}\right)\end{array}$ & $\begin{array}{c}\mathrm{K}_{2} \mathrm{O} \\
\left(\mathrm{mg} \mathrm{kg}^{-1}\right)\end{array}$ & $\begin{array}{r}\left(\mathrm{NO}_{3^{-}}+\mathrm{NO}_{2}\right)- \\
\mathrm{N}\left(\mathrm{mg} \mathrm{kg}^{-1}\right)\end{array}$ \\
\hline CR 1 P1 & $2.41_{\mathrm{ab}}$ & $5.95 \mathrm{e}$ & 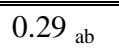 & $100.73_{\mathrm{b}}$ & $302.66_{c}$ & $3.23 \mathrm{a}$ \\
\hline CR 1 P2 & $2.21 \mathrm{a}$ & 5.33 & $0.28 \mathrm{ab}$ & $70.96_{\mathrm{ab}}$ & $217.00 \mathrm{a}$ & $5.21_{\mathrm{a}}$ \\
\hline CR 3 P1 & $2.74 \mathrm{bc}$ & 5.32 & $0.28_{\mathrm{ab}}$ & $69.46_{\mathrm{ab}}$ & $271.00 \mathrm{bc}$ & $5.57 \mathrm{a}$ \\
\hline CR 3 P2 & $2.70_{\mathrm{bc}}$ & $4.93 \mathrm{a}$ & $0.29_{\mathrm{ab}}$ & $53.06_{\mathrm{a}}$ & $218.00_{\mathrm{a}}$ & $13.56_{b}$ \\
\hline CR 5 P1 & $2.65_{\mathrm{bc}}$ & 5.75 & $0.13_{\mathrm{a}}$ & $64.06_{\mathrm{ab}}$ & $302.33_{\mathrm{c}}$ & $6.61_{\mathrm{ab}}$ \\
\hline CR 5 P2 & $2.81_{\mathrm{c}}$ & 5.60 & $0.17 \mathrm{a}$ & $55.56_{\mathrm{a}}$ & $248.33_{\mathrm{ab}}$ & $4.38 \mathrm{a}$ \\
\hline CR 7 P1 & $2.89_{\mathrm{c}}$ & $6.74_{\mathrm{f}}$ & $0.46_{b}$ & $63.10_{\mathrm{a}}$ & $292.00 \mathrm{bc}$ & $4.08 \mathrm{a}$ \\
\hline CR 7 P2 & $2.60 \mathrm{bc}$ & 5.16 & $0.14_{\mathrm{a}}$ & $83.10_{\mathrm{ab}}$ & $282.33 \mathrm{bc}$ & $4.90 \mathrm{a}$ \\
\hline
\end{tabular}

Shared lowercase letters indicate no statistical difference $(p>0.05)$ between the treatments, as determined by the Tukey test.

\section{Assessment of root colonization}

Roots were washed accurately with tap water and used for DNA extraction and for measurement of mycorrhizal colonization. Five root fragments (corresponding to $1.5 \mathrm{~g}$ fresh weight) were collected from each plant, washed and stained following the ink and vinegar technique (Vierheilig et al., 1998). The level of the mycorrhizal colonization (M\%) as well as arbuscule abundance (A\%) were determined using MYCOCALC software (www.dijon.inra.fr/mychintec/Mycocalc-prg/download.html) after examination of fungal structures inside the root according to Trouvelot et al. (1986).

\section{Molecular analysis}

The analysis of soil AMF assemblages was conducted using the sequences amplified from soil cores adjoining the roots sampled, published in Magurno et al., 2014b.

Root DNA extraction was performed from $600 \mathrm{mg}$ of washed roots per plant, following the procedure described by Khan et al. (2007). After extraction the DNA concentration was measured with NanoDrop Spectrophotometer and the final concentration was standardized to $4 \mathrm{ng} \mu \mathrm{l}^{-1}$. 
Amplification of LSU fragments (large subunit rDNA) was achieved by means of a nested approach with Phusion High Fidelity DNA Polymerase (Thermo Scientific) using LR1 (5'-GCATATCAATAAGCGGAGGA-3') and NDL22 (5'TGGTCCGTGTTTCAAGACG-3') as outer primers (van Tuinen et al., 1998) in combination with the inner primers 28G1 (5'-CATGGAGGGTGAGAATCCCG-3') and 28G2 (5'-CCATTACGTCAACATCCTTAACG-3'), specific for arbuscular mycorrhizal fungi (da Silva et al., 2006).

PCR was carried out in $40 \mu \mathrm{l}$ final volume, in a reaction mix according to Phusion High Fidelity DNA Polymerase protocol. Annealing temperatures $\left(62^{\circ} \mathrm{C}\right.$ for the first PCR and $67^{\circ} \mathrm{C}$ for the nested PCR) were calculated using the Tm calculator and instructions on Thermo Scientific website (www.thermoscientific.com/pcrwebtools). PCR products of the expected size (about $585 \mathrm{bp}$ ) were purified from agarose gel with GFX PCR DNA and Gel Band Purification Kit (GE Healthcare). Fragments were cloned into CloneJet PCR Cloning kit (Thermo Scientific) and transformed into Escherichia coli DH5 $\alpha$. Positive transformants were checked by PCR with 28G1-28G2 primers for presence and size of the insert. Twenty positive clones per transformation (480 clones totally) were sent to Beckman Coulter Genomics (United Kingdom) for plasmid extraction and sequencing.

\section{Phylogenetic analysis}

Sequence similarities were determined using the blastn sequence similarity search tool provided by GenBank. Sequences were also checked for chimeras using the "chimera.slayer" command in Mothur v.1.23.0 (Schloss et al., 2009). Given a high number of chimera detected in the full length sequences, a hypervariable region (about $255 \mathrm{bp}$, from residue 160 to 415) was trimmed and tested for suitability in phylogenetic analysis. The trimmed sequences were verified again for similarities and presence of chimera. Only sequences belonging to Glomeromycota were selected for the subsequent analysis and the others were discarded. Sequence editing was conducted manually using MEGA 6.06 and Chromas Lite 2.01. The sequences were deposited at the National Center for Biotechnology Information (NCBI) GenBank with accession numbers KR536178 - KR536609. Sequences (KM879479 - KM879872) amplified from soil cores (Magurno et al., 2014b) were trimmed as described above and included in the subsequent analysis.

Before proceeding with the sequence clustering, a small subset of about 50 sequences from isolates representing the main morphospecies of Glomeraceae was used to define the most appropriate similarity level to distinguish AMF species on the basis of the molecular target considered. Morphospecies were chosen only from the family of Glomeraceae according to the blastn results of the sequences in study.

Clustering was performed using UCLUST (Edgar, 2010) from the pipeline of Qiime (quiime.org). A level of similarity of $94.7 \%$ was chosen and applied to cluster root and soil sequences together.

Representative sequences for each MOTU were used in blastn to find reference sequences to build a phylogenetic tree. To ease the handling of data, we adopted the nomenclature proposed by Schüßler and Walker, 2010, including the modification of the genus Rhizophagus (Sieverding et al., 2014) and the introduction of two new genera (Błaszkowski et al., 2015). Reference sequences and MOTU representative sequences were aligned through the CIPRES web-portal with MAFFT on XSEDE (Miller et al., 2010). Phylogenetic tree inference, using a maximum likelihood/1000 rapid 
bootstrapping run, was computed through the CIPRES web-portal with RAxML ver. 7.3.0. To enforce the robustness of groups topology, a phylogenetic tree built with 30 LSU (560 bp long) reference sequences was used as constraint.

\section{AMF communities' structure and diversity indices}

We addressed the community structure by estimating several alfa-diversity indices per each parcel sampled. The communities were named according to the source (R: root; $\mathrm{S}$ : soil), the crop rotation type (1: monoculture; 3: alfalfa-maize rotation; 5: wheatmaize rotation; 7: Norfolk type) and the number of parcel. For example R12 was the root AMF assemblage of the parcel 2 in monoculture. Non-parametric richness indices (ACE and Chao1) and Shannon diversity index were estimated with Mothur. The standardized effect size of mean pair wise distance, SES-MPD (measure of the phylogenetic diversity considering the taxa abundances), was calculated using the picante package (Kembel et al., 2010) in R 3.0.2 (R Core Team, 2013) inputting a square distance-matrix produced by Mothur (calc=eachgap method) from the MOTU representative sequences, previously aligned with MAFFT on XSEDE. Furthermore the net relatedness index (NRI) value (measure of the clustering or segregation of the overall AMF community) was calculated using a null.model="sample.pool" and abundance.weighted=TRUE. The beta-diversity among AMF communities was evaluated as phylogenetic beta-diversity using the picante package, in order to include not only the "species" distribution but also the phylogenetic relationships among them.

\section{Statistical analysis}

Root colonization data normalized by arcsine transformation and soil data were subjected to one-way analysis of variance, using $\mathrm{R}$ software package version 3.0.2. Tukey's multiple comparison test was used to assess significant differences between pairs of mean values.

The data about MOTUs distribution were subjected to principal component analysis (PCA) and common components coefficients, eigenvalues and the proportion of the total variance expressed by each single MOTU were calculated. The analysis was implemented using the package FactoMineR (Lê et al., 2008) in R 3.0.2. Correlations between MOTUs and each principal component were calculated, and those having an absolute value $>0.5$ were considered relevant. A hierarchical clustering on principal components (HCPC) analysis was performed to define a set of clusters based on MOTUs identified. The cluster analysis was performed only on the most significant PCA components, with the remaining minor ones considered to represent noise.

A Principal Coordinate Analysis (PCoA) was computed, using the package ape in $\mathrm{R}$ 3.0.2, in order to assess the correlation between AMF assemblages on the basis of their pairwise phylogenetic distances, considering the effect of the soil variables after logtransformation ( $\mathrm{pH}-\mathrm{H}_{2} \mathrm{O}, \mathrm{pH}-\mathrm{KCl}, \mathrm{CaCO}_{3}$, Humus, $\left.\mathrm{N}, \mathrm{P}, \mathrm{K}\right)$. 


\section{Results and discussion}

\section{Root colonization}

According to the Tukey's test there were not significant differences neither in the mycorrhizal colonization (M\%) nor in the arbuscule abundance (A\%) between samples collected from the four cropping systems. The lowest level of colonization (M\%) and arbuscule abundance (A\%) were observed in the roots of maize in monoculture $(14.35 \%$ and $5.22 \%$ ) and in the roots of wheat in Norfolk type rotation (14.49\% and $2.90 \%)$. The highest values were detected in roots from the alfalfa-maize $(25.09 \%$ and $6.72 \%)$ and wheat-maize rotation (22.71\% and 8.25\%). In a previous study (Magurno et al., 2014a) the root colonization of wheat in Norfolk type was significantly higher $(p<0.01)$ than the colonization of maize roots in the other rotation systems. The difference in the results could be due to an overestimation of the colonization in wheat because of the grid-line intersect method used in the assay.

\section{Molecular and phylogenetic analysis}

DNA was extracted successfully from all the root samples with an average yield of $28 \mathrm{ng} \mu \mathrm{l}^{-1}$. All samples gave positive PCR products after the nested amplification. Overall 435 good quality sequences were analyzed with blastn without detecting any non-AMF sequence, proving the high specificity of the primers 28G1-28G2 used in the amplification. According to the blastn results $100 \%$ of AMF sequences belonged to the family Glomeraceae (Schüßler and Walker, 2010; Redecker et al., 2013). The result is in agreement with several studies conducted on agro-ecosystem where land-use intensification through tillage, fertilizers, biocides and crop rotations negatively affects AMF richness promoting the occurrence of members of Glomeraceae due to their disturbance-tolerant and opportunistic behavior (Ijdo et al., 2010; Lumini et al., 2010; Verbruggen et al., 2012).

After trimming and chimera-checking, three sequences were discarded. The remaining 432 sequences ( 255 bp long) were pooled with 446 trimmed sequences from a previous analysis of the AMF community in the soil and then clustered by UCLUST in 29 MOTUs according to $94.7 \%$ similarity level. The representative sequences for each MOTU were used to build a phylogenetic tree (Fig. 1) with the reference sequences identified by blastn.

Considering the relative abundance of the MOTUs and their position in the phylogenetic tree, the genus Rhizoglomus (former Rhizophagus, Sieverding et al., 2014) resulted the most represented with $73.1 \%$ of root sequences and $28 \%$ of soil sequences. The genus Funneliformis was the second most represented with $8.1 \%$ of root sequences and $15.2 \%$ of soil sequences, followed by Septoglomus $(7.6 \%$ of root sequences and $6.7 \%$ of soil sequences), Dominikia (3\% and 5.2\%), Sclerocystis (2.3\% and $4 \%$ ) and Kamienskia (0\% and 2.5\%). The remaining sequences were found in MOTUs related to Glomus species of uncertain affiliation clustering basal in the Glomeraceae. According to the phylogenetic tree these MOTUs were divided in four clades (Glomus sensu lato group 1-4). 

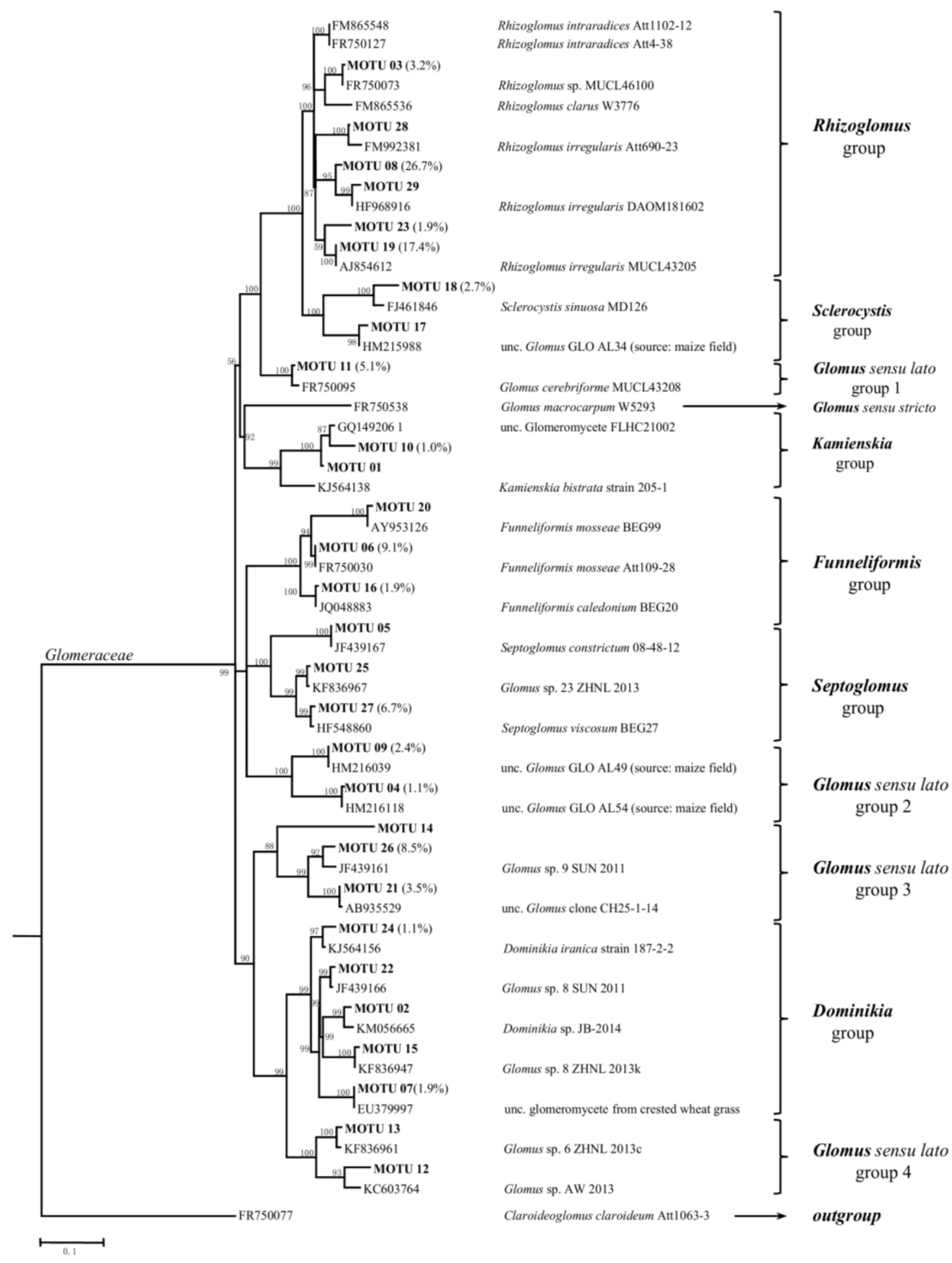

Figure 1. Maximum likelihood phylogenetic analysis of arbuscular mycorrhizal fungal LSU rDNA sequences. The phylogenetic tree was built using representative sequences of 29 MOTUs, identified by UCLUST at $94.7 \%$ similarity level, and 31 reference sequences. In brackets the percentage (when >1) of sequences clustering in the MOTU is reported. Beside the nodes, bootstrap values $>50$ were reported. MOTUs were grouped according to the related genus when it was possible to determinate. Claroideoglomus claroideum FR750077 was included as outgroup 


\section{AMF communities' structure, diversity and overlap}

MOTUs distribution and relative abundance were analyzed for each parcel in each rotation system (Fig. 2). To simplify the interpretation of data the analysis was conducted considering the macro-clades illustrated in the phylogenetic tree (Rhizoglomus group, Funneliformis group...). In the root AMF communities, with the exception of the parcel R11, an overdominance of the Rhizoglomus group was observed. The relative abundance of Rhizoglomus MOTUs increased substantially from monoculture to Norfolk type root communities. Considering an average between the two parcels per rotation, a relative abundance of $49 \%$ was found in maize monoculture, $74 \%$ in alfalfa-maize rotation, $75 \%$ in wheat-maize rotation and $93.5 \%$ in Norfolk type. Rhizoglomus species are known to be widespread generalists, detected in a range of habitats, colonizing a number of different plant species (Öpik et al., 2006). Considering the influence of the host specificity in the plant-symbiont interaction (Helgason et al., 2007), the number of crops involved in a rotation could be correlated with a positive selection towards those taxa that, as generalists, represent an "optimal" symbiont for a high number of plant species (Magurno et al., 2014a).

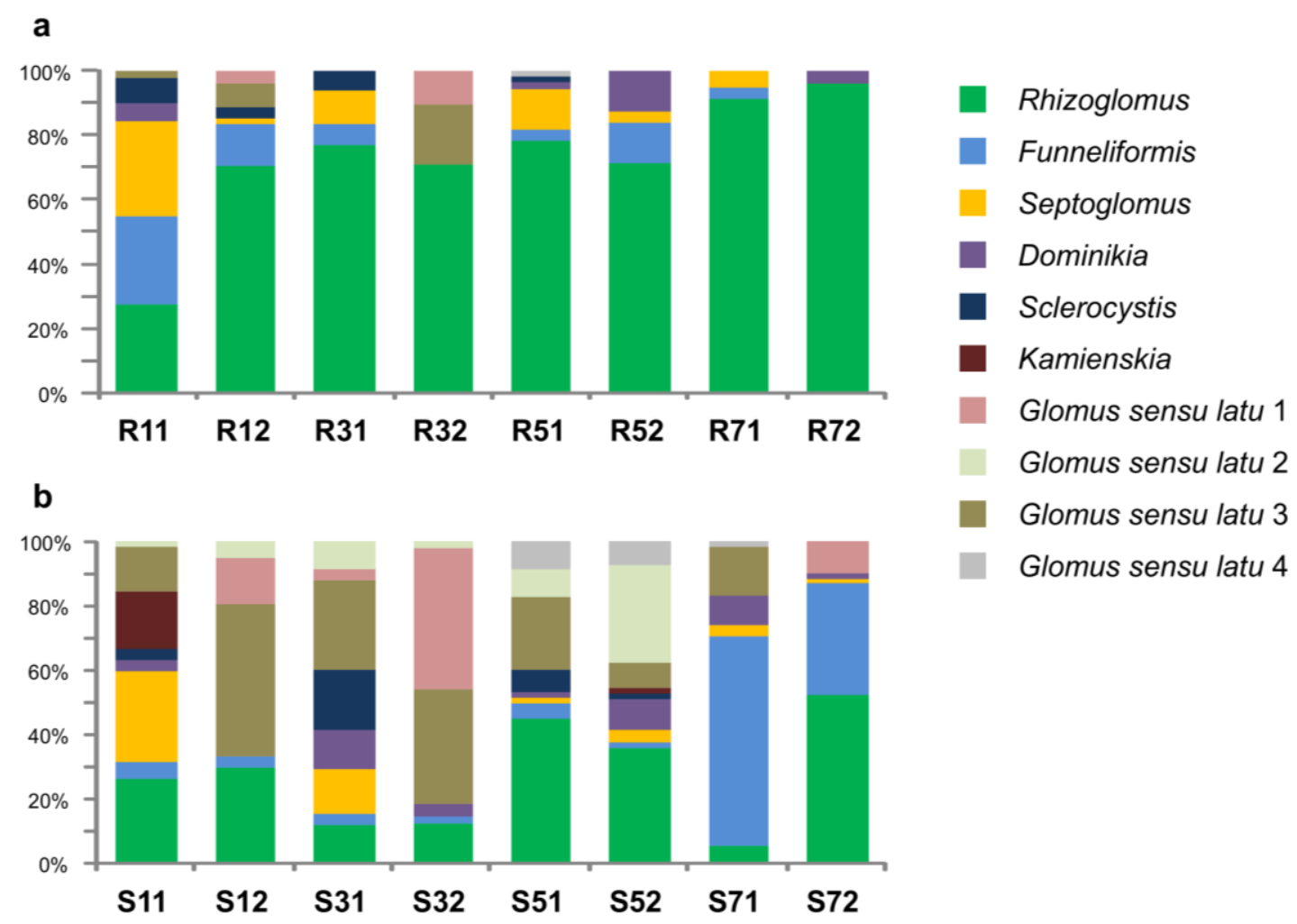

Figure 2. Distribution of AMF phylotypes detected in the root samples (a) and in the soil samples (b). In the histograms AMF taxa were represented by groups, corresponding to the rank genus, as described in the phylogenetic tree. Crop rotations: maize monoculture (R1, S1), alfalfa-maize (R3, S3), wheat-maize (R5, S5), Norfolk type (R7, S7)

In the soil AMF communities the distribution of MOTUs was more uniform with the exception of the parcel S71 where the group Funneliformis was overdominant. MOTUs belonging to the Glomus sensu lato group 4 were well represented in almost all the parcels while in the root AMF communities their presence was less significant. 
To evaluate a possible correlation between the crop rotations and the composition and structure of AMF communities the overlap among the root and soil AMF assemblages was computed by means of a Principal Component Analysis (PCA) (Fig. 3). Principal component 1 (35.02\%) and 2 (17.86\%) explained about 53\% of the experimental variance, with a high correlation with the five most abundant MOTUs detected (MOTU08 and MOTU19, Rhizoglomus group; MOTU06, Funneliformis group; MOTU26, Glomus sensu lato group 4; MOTU11, Glomus sensu lato group 1). The PCA, supported by a hierarchical clustering on principal components analysis, showed six main clusters. All the root AMF assemblages were found in the same cluster with the exception of monoculture assemblages (R11 and R12) that clustered separately together with S11, S31 and S52. The remaining soil AMF assemblages did not show any correlation between crop rotation type and specific clusters.

\section{Individuals factor map (PCA)}

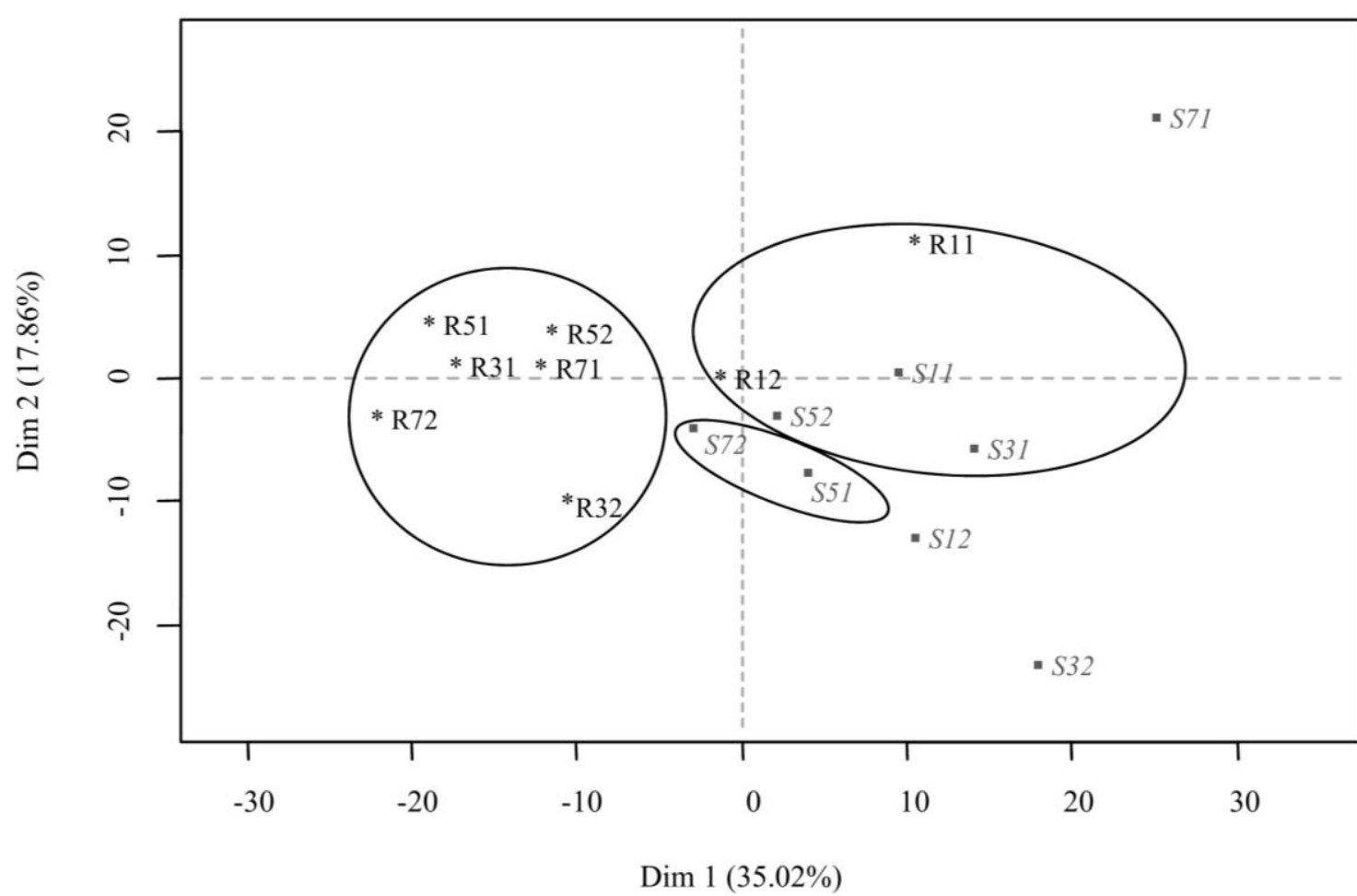

Figure 3. PCA biplot of the AMF communities found in the soil (asterisk) and in the maize roots (square) for the four different crop rotations. The circles represent the clusters according to the $\mathrm{HCPC}$

Furthermore a Principal Coordinate Analysis (PCoA) (Fig. 4) was computed on the basis of pairwise phylogenetic distances of the assemblages and the soil variables. The analysis confirmed the results of the PCA, highlighting a possible influence of the nitrogen on the position of R11 and S32 on the opposite sides of the plot.

The lack of correlation between treatments and the taxa composition of AMF assemblages could be related to the findings of several studies where, beside nichebased mechanisms (Balestrini et al., 2010; Sasvári et al., 2011), the role of stochastic-neutral processes was highly involved in the shaping of AMF 
communities (Dumbrell et al., 2010; Lekberg et al., 2012). Analysis conducted in the same experimental field in 2008 have shown on the contrary an influence of the crop rotation on the composition of the AMF community (Magurno et al., 2014a). The discordance with the present results could be explained by the different gene target used and the lower number of clones sequenced in the previous study. With the primers AMV4.5F- AMV4.5F, for example, it was possible to detect one Rhizoglomus MOTU vs. the six found in the present analysis.

The PCA and PCoA did not highlight any correlation between the root and soil communities belonging to the same parcel. This result is actually misleading. Because the root AMF community is supposed to be a subgroup of the related soil AMF community, for each parcel the number of MOTUs shared between root and soil communities was divided per the total number of MOTU detected in the root assemblage. The resulting value was used as index of overlapping for the parcel. The percentages of overlapping ranged between $67 \%$ and $100 \%$, confirming a high correlation between root and the related soil communities. The relative abundance of MOTUs was not considered because of the "distorted" abundances in the roots due to the overdominance of Rhizoglomus MOTUs.

\section{PCoA biplot \\ Response variables projected as in PCA with scaling 1}

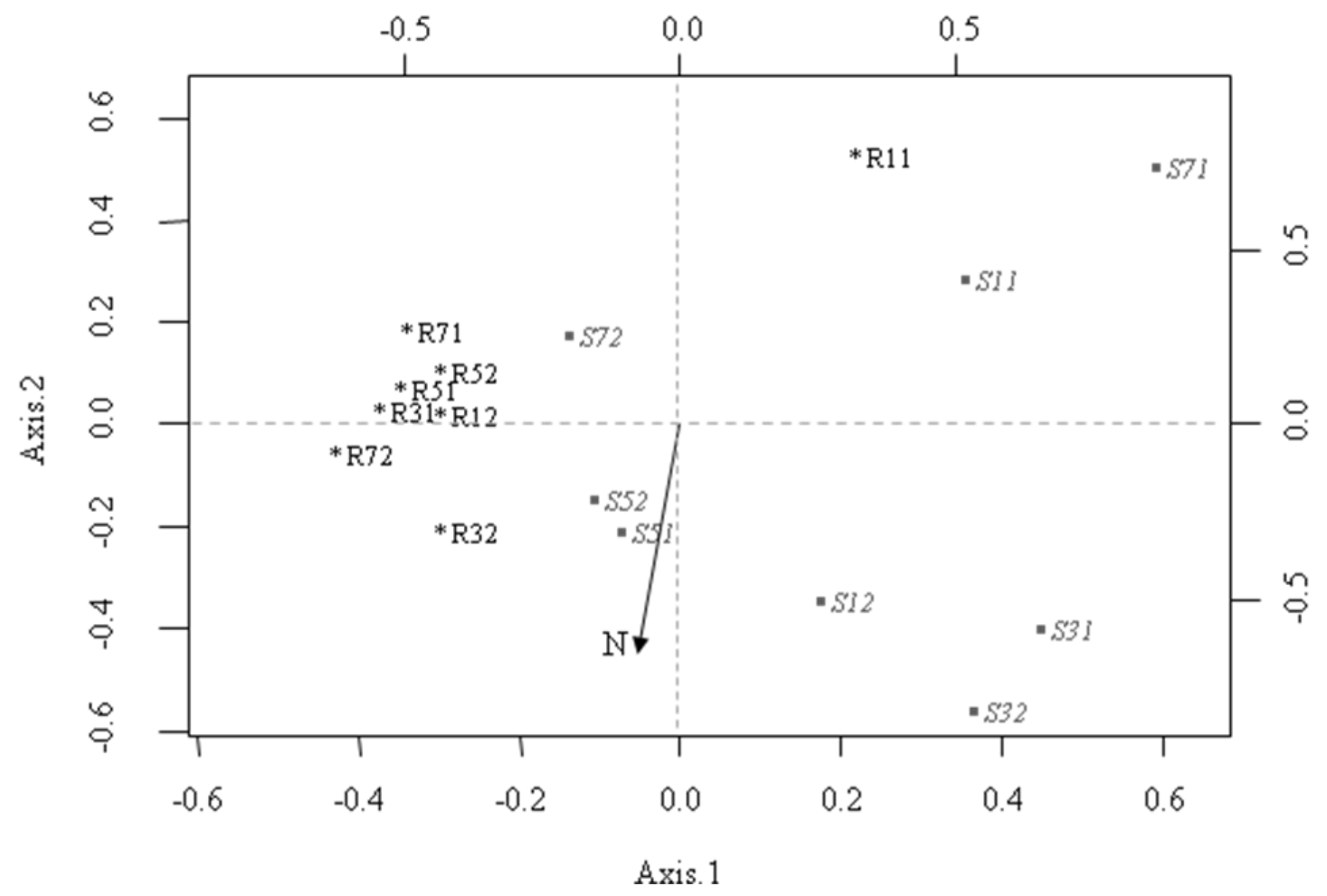

Figure 4. Principal Coordinate Analysis (PCOA) conducted on the basis of pairwise phylogenetic distances among the AMF assemblages and including the log-transformed soil variables as explanatory variables (only $N$ is shown) 
On the basis of the alfa-diversity predicted by ACE and Chao1 (Table 2) it was possible to estimate the level of richness collected by the sampling. On average $88 \%$ of the total richness predicted was represented by the MOTUs observed. The biodiversity, as number of MOTUs estimated and Shannon index, decreased strongly from the monoculture to Norfolk type in the root AMF assemblages. Even though less severe, an opposite trend was observed in the soil AMF assemblages, where the highest richness predicted was found in the wheat-maize rotation S5.

Table 2. Observed versus estimated MOTUs, based on ACE and Chaol non-parametric richness estimators, Shannon-Weaver diversity indices $\left(H^{\prime}\right)$, standardized effect size of mean pair wise distances (SES-MPD) and the net relatedness index (NRI). The values represent the mean of the two parcels per each rotation type in the root $(R)$ and soil $(S)$ compartments. Monoculture: R1, S1; alfalfa-maize: R3, S3; wheat-maize: R5, S5; Norfolk type: R7, S7

\begin{tabular}{|c|c|c|c|c|c|c|c|c|}
\hline \multirow{2}{*}{$\begin{array}{l}\text { Crop } \\
\text { rotation }\end{array}$} & \multirow{2}{*}{$\begin{array}{l}\text { Observed } \\
\text { MOTUs }\end{array}$} & \multirow{2}{*}{$\begin{array}{l}\text { SES- } \\
\text { MPD }\end{array}$} & \multirow[b]{2}{*}{ NRI } & \multicolumn{3}{|c|}{ Estimated MOTUs } & \multirow{2}{*}{$\mathrm{O} / \mathrm{E}^{\mathrm{a}}$} & \multirow{2}{*}{$\begin{array}{l}\text { Shannon } \\
\text { Index H' }\end{array}$} \\
\hline & & & & $\mathrm{ACE}$ & Chao1 & $\begin{array}{c}\text { Average } \\
\text { A-C }\end{array}$ & & \\
\hline R1 & 9.0 & 0.14 & 2.57 & 11.8 & 10.7 & 11.2 & 80.3 & 1.8 \\
\hline $\mathrm{R} 3$ & 5.5 & 0.10 & 2.74 & 5.8 & 5.5 & 5.6 & 97.6 & 1.3 \\
\hline $\mathrm{R} 5$ & 6.5 & 0.10 & 2.57 & 10.0 & 7.3 & 8.6 & 75.4 & 1.4 \\
\hline R7 & 5.0 & 0.06 & 3.82 & 5.5 & 5.0 & 5.3 & 95.2 & 1.1 \\
\hline S1 & 9.5 & 0.16 & 0.23 & 10.3 & 9.7 & 10.0 & 95.3 & 1.9 \\
\hline S3 & 8.0 & 0.16 & -0.22 & 12.3 & 11.4 & 11.9 & 67.3 & 1.7 \\
\hline S5 & 13.5 & 0.17 & 0.24 & 18.1 & 16.6 & 17.4 & 77.8 & 2.2 \\
\hline S7 & 8.0 & 0.12 & 1.35 & 12.1 & 9.5 & 10.8 & 74.2 & 1.5 \\
\hline
\end{tabular}

Regarding the standardized effect size of mean pairwise distance (SES-MPD) (Table 2), explaining the phylogenetic diversity of taxa inside an AMF community, for root AMF assemblages the index decreased from monoculture (R1, S1) to Norfolk type (R7, S7). In the soil community the values, as expected, were higher than the root communities because of wider range of MOTUs detected. Among the soil communities, a similar value of SES-MPD was found among all the treatments with the exception of the Norfolk type assemblages where it was lower.

The net relatedness index (NRI) gives a measure of the clustering or segregation of the AMF community. NRI was positive for all the root assemblages and the highest value was detected in the Norfolk type treatment. In the soil communities the values were lower compared to the former.

Monoculture (S1) and wheat-maize rotation (S5) shared a similar NRI value (0.23; $0.24)$ while a negative NRI was found for alfalfa-maize rotation (S3) (-0.22). On the other hand the Norfolk type rotation showed a high positive value (1.35).

The level of relatedness among taxa in the AMF assemblages and the indices of richness considered could provide a key to interpret the effect of different crop rotations on the AMF community. The maize monoculture was found to host in the 
soil and root compartment a high diversity both as number of taxa predicted and level of phylogenetic diversity SES-MPD. While neutral processes could have played a major role on the composition, a significant community clustering, as observed particularly in the root assemblages, might be evidence of positive ecological interactions (Vamosi et al., 2009), represented, in this case, by a long term stable relationship among host and AMF community. Compared to monoculture, the wheat-maize rotation root AMF community was characterized by a lower alfa-diversity (taxa predicted and SES-MPD) with a similar level of clustering. In the soil assemblages the number of taxa estimated was significantly higher than in monoculture while SES-MPD and NRI were similar.

Assuming preferential host-symbiont associations as an environmental filter, the two crops involved in the rotation, wheat and maize, could have selected, in the long term, their own AMF communities, inducing an overall increase of the richness in the soil. As a consequence at root level the "host preferential" AMF community would have taken advantage in the colonization causing a reduction in the diversity. It would be expected to find, at soil level, a community overdispersion (assemblages made up of distantly related organisms) but the NRI value was similar to that calculated in monoculture. A possible explanation could rely upon the fact that maize and wheat belong to the same family (Poaceae) and thus they could have similar "criteria" in the selection of preferential AMF communities. This hypothesis could explain the alfalfa-maize rotation outcomes where a lowly diverse but clustered community was detected at root level, while a richer and slightly overdispersed community was present in the soil. In this case alfalfa and maize, given their long permanence in the field ( 3 years alfalfa, 5 years maize), would represent a reduced niche overlap for the related AMF communities with a negative effect on the overall soil community clustering (Cavender-Bares et al., 2009). In Norfolk type treatment, wheat was present instead of maize at the sampling times. Even considering the possible influence of a different host on the structure of the AMF community, the data about root and soil assemblages were fitting with the "preferential associations" model proposed. In the root assemblages the richness and phylogenetic diversity were indeed extremely low while the level of community clustering was the highest among all the assemblages due to strong relatedness among the taxa detected. In the soil (S7) the richness predicted was slightly higher compared to the monoculture but the SES-MPD value was the lowest among all the soil assemblages. Unlike the alfalfamaize rotation, in the Norfolk type permanence in the field of the four crops in rotation was limited to one year per crop. Instead of an overdispersion for reduced niche overlap, the fast succession of crops promoted the selection of a clustered AMF generalist community, characterized by a number of predicted taxa comparable with the monoculture but with the highest relatedness among the taxa. Indeed the dominant MOTUs found in S7 were related to the generalist taxa Funneliformis mosseae and Rhizoglomus irregularis (Oehl et al., 2010).

\section{Conclusions}

In conclusion the analysis of the AMF communities associated to different crop rotations did not reveal any influence of the treatments on the composition of the communities, where stochastic processes play probably a major role. At the same time the results were in agreement with Magurno et al. (2014a), about a gradient of diversity in the root communities, decreasing from monoculture to Norfolk type rotation. 
Furthermore, considering root and soil communities, the analysis of the phylogenetic diversity and the index of relatedness, shined a light on a possible model to interpret the correlation between rotation system and structure of AMF communities.

Acknowledgements. The authors thank Dr Zoltán Berzsenyi and Péter Bónis for the valuable advice and helpful comments on field experiments and Mark Gebel for manuscript proofreading. This study was financially supported by grants from the National Research Council (OTKA K101878) and by the Research Centre of Excellence-9878/2015/FEKUT.

\section{REFERENCES}

[1] Arihara, J., Karasawa, T. (2000): Effect of previous crops on arbuscular mycorrhizal formation and growth of succeeding maize. - Soil Science and Plant Nutrition 46: 43-51.

[2] Augé, R.M. (2001): Water relations, drought and VA mycorrhizal symbiosis. Mycorrhiza 1: 3-42.

[3] Balestrini, R., Magurno, F., Walker, C., Lumini, E., Bianciotto, V. (2010): Cohorts of arbuscular mycorrhizal fungi (AMF) in Vitis vinifera, a typical Mediterranean fruit crop. - Environmental Microbiology Reports 2: 594-604.

[4] Bardgett, R.D., Usher, M.B., Hopkins, D.W. (2005): Biological diversity and function in soils. 1st ed. Cambridge: Cambridge University Press, 2005. Cambridge Books Online. Web. 05 May 2015.

[5] Berruti, A., Borriello, R., Orgiazzi, A., Barbera, A.C., Lumini E., Bianciotto V. (2014): Arbuscular Mycorrhizal Fungi and their Value for Ecosystem Management. - In: PhD. Oscar Grillo (ed.). Biodiversity - The Dynamic Balance of the Planet.

[6] Berzsenyi, Z., Győrffy, B., Lap, D. (2000): Effect of crop rotation and fertilisation on maize and wheat yields and yield stability in a long-term experiment. - European Journal of Agronomy 13(2-3): 225-244.

[7] Błaszkowski, J., Chwat, G., Góralska, A., Ryszka, P., Kovács, G.M., 2015. Two new genera, Dominikia and Kamienskia, and D. disticha sp. nov. in Glomeromycota. Nova Hedwigia 100, 225-238.

[8] Burrows, R.L., Pfleger, F.L. (2002): Arbuscular mycorrhizal fungi respond to increasing plant diversity. - Canadian Journal of Botany 80: 120-130.

[9] Cavender-Bares, J., Kozak, K.H., Fine, P.V.A., Kembel, S.W. (2009): The merging of community ecology and phylogenetic biology. - Ecology Letters 12: 693-715.

[10] da Silva, G.A., Lumini, E., Maia, L.C., Bonfante, P., Bianciotto, V. (2006): Phylogenetic analysis of Glomeromycota by partial LSU rDNA sequences. - Mycorrhiza 16: 183-189.

[11] Dumbrell, A.J., Nelson, M., Helgason, T., Dytham, C., Fitter, A.H. (2010): Relative roles of niche and neutral processes in structuring a soil microbial community. - The ISME Journal 4: 337-345.

[12] Edgar, R.C. (2010): Search and clustering orders of magnitude faster than BLAST. Bioinformatics 26: 2460-2461.

[13] FAO (2012): Food and Agriculture Organization of the United Nations, Land Resources. FAOSTATS-Crops. http://faostat.fao.org/site/567/default.aspx\#ancor

[14] Gianinazzi, S., Vosátka, M. (2004): Inoculum of arbuscular mycorrhizal fungi for production systems: science meets business. - Canadian Journal of Botany 82: 12641271.

[15] Helgason, T., Merryweather, J.W., Young, J.P.W., Fitter, A.H. (2007): Specificity and resilience in the arbuscular mycorrhizal fungi of a natural woodland community. - Journal of Ecology 95: 623-630. 
[16] Higo, M,, Isobe, K., Yamaguchi, M., Ishii, R., Drijber, R.A., Jeske, E.S. (2013): Diversity and vertical distribution of indigenous arbuscular mycorrhizal fungi under two soybean rotational systems. - Biology and Fertility of Soils 49(8): 1085-1096.

[17] Hijri, I., Sýkorová, Z., Oehl, F., Ineichen, K., Mäder, P., Wiemken, A., Redecker, D. (2006): Communities of arbuscular mycorrhizal fungi in arable soils are not necessarily low in diversity. - Molecular Ecology 15: 2277-2289.

[18] Ijdo, M., Schtickzelle, N., Cranenbrouck, S., Declerck, S. (2010): Do arbuscular mycorrhizal fungi with contrasting life history strategies differ in their responses to repeated defoliation? - FEMS Microbiology Ecology 72: 114-122.

[19] Kembel, S.W., Cowan, P.D., Helmus, M.R., Cornwell, W.K., Morlon, H., Ackerly, D.D. et al. (2010): Picante: R tools for integrating phylogenies and ecology. - Bioinformatics 26: $1463-1464$.

[20] Khan, S., Qureshi, M.I., Alam, K.T., Abdin, M.Z. (2007): Protocol for isolation of genomic DNA from dry and fresh roots of medicinal plants suitable for RAPD and restriction digestion. - African Journal of Biotechnology 6(3): 175-178.

[21] Lekberg, Y., Koide, R.T. (2005): Is plant performance limited by abundance of arbuscular mycorrhizal fungi? A meta-analysis of studies published between 1988 and 2003. - New Phytologist 168: 189-204.

[22] Lekberg, Y., Schnoor, T., Kjøller, R., Gibbons, S.M., Hansen, L.H., Al-Soud, W.A., Sørensen, S.J., Rosendahl, S. (2012): 454-sequencing reveals stochastic local reassembly and high disturbance tolerance within arbuscular mycorrhizal fungal communities. Journal of Ecology 100: 151-160.

[23] Lê, S., Josse, J., Husson, F. (2008): FactoMineR: An R package for multivariate analysis. - Journal of Statistical Software 25(1).

[24] Lumini, E., Orgiazzi, A., Borriello, R., Bonfante, P., Bianciotto, V. (2010): Disclosing arbuscular mycorrhizal fungal biodiversity in soil through a land use gradient using a pyrosequencing approach. - Environmental Microbiology 12: 2165-2179.

[25] Magurno, F., Sasvári, Z., Posta, K. (2014a): From monoculture to the Norfolk system: assessment of arbuscular mycorrhizal fungi communities associated with different crop rotation systems. - Symbiosis 64(3): 115-125.

[26] Magurno, F., Sasvári, Z., Barchi, L., Posta, K. (2014b): From Monoculture to Norfolk System: How the Number of Crops in Rotation Can Influence the Biodiversity of Arbuscular Mycorrhiza Assemblages in the Soil. - Open Journal of Ecology 4: 10801088.

[27] Miller, M.A., Pfeiffer, W., Schwartz, T. (2010): Creating the CIPRES Science Gateway for inference of large phylogenetic trees. - In: Proceedings of the Gateway Computing Environments Workshop (GCE). New Orleans, LA.

[28] Oehl, F., Sieverding, E., Ineichen, K., Mader, P., Boller, T., Wiemken, A. (2003): Impact of land use intensity on the species diversity of arbuscular mycorrhizal fungi in agroecosystems of central Europe. - Applied Environmental Microbiology 69: 28162824.

[29] Oehl, F., Laczko, E., Bogenrieder, A., Stahr, K., Bösch, R., van der Heijden, M.G.A., Sieverding, E. (2010): Soil type and land use intensity determine the composition of arbuscular mycorrhizal fungal communities. - Soil Biology and Biochemistry 42: 724738.

[30] Öpik, M., Moora, M., Liira, J., Zobel, M. (2006): Composition of root-colonizing arbuscular mycorrhizal fungal communities in different ecosystems around the globe. Journal of Ecology 94: 778-790.

[31] Pozo, M.J., Azcón-Aguilar C. (2007): Unraveling mycorrhiza-induced resistance. Current Opinion in Plant Biology 10: 393-398.

[32] R Core Team (2013): R: A Language and Environment for Statistical Computing. R Foundation for Statistical Computing: Vienna. 
[33] Redecker, D., Schüssler, A., Stockinger, H., Stürmer, S.L., Morton, J.B., Walker, C. (2013): An evidence-based consensus for the classification of arbuscular mycorrhizal fungi (Glomeromycota). - Mycorrhiza 23: 515-531.

[34] Roger, A., Colard, A., Angelard, C., Sanders, I.R. (2013): Relatedness among arbuscular mycorrhizal fungi drives plant growth and intraspecific fungal coexistence. - The ISME Journal 7(11): 2137-2146.

[35] Sasvári, Z., Hornok, L., Posta, K. (2011): The community structure of arbuscular mycorrhizal fungi in roots of corn grown in a 50-year monoculture. - Biology and Fertility of Soils 47: 167-176.

[36] Schloss, P.D., Westcott, S.L., Ryabin, T., Hall, J.R., Hartmann, M., et al. (2009): Introducing mothur: Open-source, platform-independent, community-supported software for describing and comparing microbial communities. - Applied Environmental Microbiology 75: 7537-7541.

[37] Schüßler, A., Walker, C., 2010. The Glomeromycota: a species list with new families and genera, Arthur Schüßler \& Christopher Walker, Gloucester.

[38] Sieverding, E., da Silva, G.A., Berndt, R., Oehl, F., 2014. Rhizoglomus, a new genus of the Glomeraceae. Mycotaxon 129(2), 373-386.

[39] Smith, S.E., Read, D.J. (2008): Mycorrhizal Symbiosis, 3rd edn. Academic Press: London.

[40] Trouvelot, A., Kough, J.L., Gianinazzi-Pearson, V. (1986): Mesure du taux de mycorhization VA d'un système radiculaire. Recherche de méthodes d'estimation ayant une signification fonctionnelle. - In: Gianinazzi-Pearson V., Gianinazzi S. (eds.), Physiological and Genetical Aspects of Mycorrhizae, INRA Press, Paris: 217-221.

[41] Vamosi, S., Heard, S., Vamosi, J., Webb, C. (2009): Emerging patterns in the comparative analysis of phylogenetic community structure. - Molecular Ecology 18: 572592.

[42] van Tuinen, D., Zhao, B., Gianinazzi-Pearson, V. (1998): PCR in studies of AM fungi: from primers to application. In: Varma, A. (ed.), Mycorrhiza manual, Springer, Heidelberg: 387-399.

[43] Verbruggen, E., van der Heijden, M.G.A., Weedon, J.T., Kowalchuk, G.A., Roling, W.F.M. (2012): Community assembly, species richness and nestedness of arbuscular mycorrhizal fungi in agricultural soils. - Molecular Ecology 21: 2341-2353.

[44] Verbruggen, E., van der Heijden, M.G.A., Rillig, M.C., Kiers, E.T. (2013): Mycorrhizal fungal establishment in agricultural soils: factors determining inoculation success. - New Phytologist 197: 1104-1109.

[45] Vierheilig, H., Coughlan, A.P., Wyss, U., Piche, Y. (1998): Ink and vinegar, a simple staining technique for arbuscular-mycorrhizal fungi. - Applied Environmental Microbiology 64(12): 5004-5007. 